\title{
Decisão Judiciária: estudo do pensamento de Robert Alexy
}

\author{
Judicial decision: studies on Robert Alexy's thoughts
}

\author{
Marcos Antônio Striquer Soares ${ }^{1}$ \\ Priscila Rosa Lima ${ }^{2}$
}

\section{Resumo}

\begin{abstract}
Analisa os parâmetros que o juiz deve ter em vista para dar uma decisão, a decisão judicial, diante de casos concretos e que indicam até onde vai sua liberdade. Tem como marco teórico os estudos de Robert Alexy, a partir do qual são feitas análises sobre a colisão de direitos e a adoção da proporcionalidade para solucionar essa colisão de direitos; sobre a inclusão da moral na decisão judicial; sobre a busca da justiça; sobre o uso da ponderação nas decisões judiciárias, tendo em vista as relações entre o direito e a moral. Analisa, por fim, a necessidade de uma teoria da argumentação jurídica que possibilite uma decisão judicial coerente.
\end{abstract}

Palavras-Chave: Decisão judiciária. Proporcionalidade. Sopesamento de argumentos.

\section{Abstract}

It analyses the parameters that a judge must have in mind to take a decision; the judicial decision, when facing concrete facts, pointing out to which extent his freedom goes. The theoretical framework is based on studies on Robert Alexy, from which analysis are made about the collision of rights and the adoption of proportionality to solve this collision of rights. Moreover, the analysis tackles the inclusion of moral in judicial decisions; the search for justice; the use of weighting in judicial decisions, having in mind the relationship between law and moral. To conclude, it analyses the necessity of a law argumentation theory which would allow a coherent judicial decision.

Keywords: Judicial decision. Proportionality. Weighs of arguments.

\section{Introdução}

O trabalho tem como objetivo desenvolver o pensamento de Robert Alexy, a partir do estudo inicial das regras e dos princípios. O assunto foi delimitado buscando-se foco na

1 Mestre e doutor em Direito do Estado/Direito Constitucional pela PUC/SP; professor de Direito Constitucional na graduação em Direito, na especialização em Direito do Estado e no mestrado em Direito Negocial na Universidade Estadual de Londrina; é professor de Direito Constitucional na Universidade Norte do Paraná (UNOPAR).

2 Graduanda do curso de Direito da Universidade Estadual de Londrina. 
decisão judiciária, ou seja, nos parâmetros em que o juiz deve/pode pautar-se para decidir. Sua escolha não é arbitrária, mas deve pautar-se em fundamentos.

Robert Alexy, filósofo alemão, apresenta a máxima da proporcionalidade sob uma visão dada pelo Tribunal Constitucional Alemão. Ele traça métodos aparentemente racionais de solução de conflitos, nos quais a máxima da proporcionalidade é observada em três aspectos, a saber: adequação, exigibilidade e proporcionalidade em sentido estrito.

Mais adiante, disserta-se sobre o conceito e a validade do direito, explorando-se as dificuldades da decisão judiciária em casos tidos como difíceis, em que paira a dúvida do julgador. São casos nos quais não há decisão simples, uma vez que a simples leitura da lei não satisfaz ao magistrado e à sociedade na busca da justiça e sendo, por isso, preciso traçar métodos capazes de validar o direito.

Aqui Alexy defende a necessária conexão entre direito e moral; o juiz, ao decidir, não deve basear-se pura e simplesmente no direito posto, antes deve buscar elementos na moral, sendo essa moral obrigatoriamente justificável, para que se tenha certeza de que se trata de uma moral correta.

O trabalho tem como objetivo verificar quais são os fundamentos da teoria de Robert Alexy que permitem ao julgador recorrer a meios que se encontram fora do direito posto, previsto para solucionar o conflito. Tais fundamentos encontram-se na moral.

\section{Colisão de direitos e a proporcionalidade}

A sociedade evolui e o direito deve estar atento para acompanhar as mudanças. 0 julgador, ao decidir o caso concreto, deve estar embasado em conhecimento e ter um mínimo de "livre arbítrio" para usá-lo.

Alexy inicia sua análise estudando os princípios e, conforme Virgílio Afonso da Silva (2003, p. 4-6), acredita que um princípio pode ser um mandamento nuclear do sistema, como pode também não o ser, já que uma norma é um princípio apenas em razão de sua estrutura normativa e não de sua fundamentalidade.

Em sua "Teoria de los Derechos Fundamentales" (2002, p. 89 e segs.), Alexy trata da sua "Lei de Colisão" para solucionar a colisão de princípios. O autor parte de um julgado do Tribunal Constitucional Alemão, o qual tratou da não realização de uma audiência oral 
devido à saúde delicada do acusado que sofria risco de infarto. Nesse caso, houve a colisão entre o princípio da aplicação do direito penal P1 (que obriga a audiência oral) com o princípio de proteção do direito à vida e integridade do acusado P2 (que proibia no caso em tela a audiência oral) ${ }^{3}$.

A partir desse caso, Robert Alexy adentra em sua teoria apoiando-se, essencialmente, no postulado da proporcionalidade. Para ele, a máxima da proporcionalidade consiste na verificação dos meios utilizados para a adequação do caso concreto ao fim, por meio da ponderação. Diante de uma colisão entre direitos fundamentais, busca-se, primeiramente, a solução do conflito de acordo com o meio adequado: trata-se da adequação dos meios disponíveis; posteriormente, há que se verificar a exigibilidade do meio escolhido; e, por fim, caso não se tenha ainda solucionado a colisão, deve-se proceder à ponderação.

Isso significa utilizar-se do meio mais adequado para a persecução do fim almejado, sem que nenhum dos princípios seja infringido. Dita o Tribunal Constitucional Alemão: "Quanto mais intensa se revelar a intervenção em um dado direito fundamental, maiores hão de se revelar os fundamentos justificadores dessa intervenção". Na ponderação há o sopesamento para se definir racionalmente qual dos princípios em conflito deverá ter o maior peso no caso concreto em tela.

E quando da colisão entre princípios e regras? Para Alexy (2002, p. 134), por apresentar menor generalidade e maior grau de certeza, as regras prevalecem sobre os princípios. Esta é sua conclusão:

Por lo tanto, entre los dos niveles no existe uma relación estricta de precedência. Más bien, vale la regla de precedência según la cual el nível de lãs reglas precede al de los princípios, a menos que lãs razones para determinaciones diferentes a lãs tomadas em el nível de lãs reglas sean tan fuertes que también desplacen al principio de la sujeción al texto de la Constitución.

A questão é como esse princípio pode ser aplicado. Willis Santiago Guerra Filho, em seu livro "Teoria da Ciência Jurídica" (2001, p. 153), traz os desdobramentos da teoria de

\footnotetext{
3 Sobre a origem do princípio da proporcionalidade no Direito Alemão é possível consultar Willis Santiago Guerra Filho, Princípio da proporcionalidade e devido processo Legal; In.: Silva, Virgílio Afonso (Org.). Interpretação constitucional. São Paulo Malheiros, 2005.
} 
Alexy, conforme apresentada pelo Direito Constitucional alemão. Assim, a máxima da proporcionalidade desdobra-se em três aspectos, a saber: adequação, exigibilidade e proporcionalidade em sentido estrito, conforme segue:

\footnotetext{
Sempre se tem em vista o fim colimado nas disposições constitucionais a serem interpretadas, fim esse que pode ser atingido por diversos meios, dentre os quais se haverá de optar. O meio a ser escolhido deverá, em primeiro lugar, ser adequado para atingir o resultado almejado, revelando conformidade e utilidade ao fim desejado.
}

Tem-se aqui a adequação, ou seja, a interpretação dos dispositivos constitucionais deverá ser pautada por meios adequados para atingir o resultado almejado.

Em seguida proceder-se-á à exigibilidade. Esta significa que será preciso provar a exigibilidade do meio, o que quer dizer, se dois meios podem ser utilizados para proceder à interpretação, deverá ser utilizado o que se mostra como o "'mais suave' dentre os diversos disponíveis, o menos agressivo aos bens e valores constitucionalmente protegidos, que porventura colidem com aquele consagrado na norma interpretada" (GUERRA, 2001, p. 154).

Por fim, deve-se respeitar a proporcionalidade em sentido estrito, em outras palavras, deve-se assegurar que "o meio a ser empregado se mostra o mais vantajoso, no sentido da promoção de certos valores com o mínimo de desrespeito de outros que a eles se contraponham, observando-se, ainda, que não haja violação do 'mínimo' em que todos devem ser respeitados" (GUERRA, 2001, p. 154).

Virgílio Afonso da Silva (2002, p. 32) afirma que o princípio da proporcionalidade, na teoria de Robert Alexy, não pode ser considerado um princípio, pelo menos não com base em sua classificação, pois não há como produzir efeitos em variadas medidas, já que é aplicado de forma constante, sem variações. Contudo, como adverte Willis Santiago Guerra Filho (2005, p. 268), o fato de os "subprincípios da proporcionalidade" permitirem, tal como regras jurídicas, o sopesamento "não implica ser o princípio da proporcionalidade uma regra, pois o conteúdo de uma regra é a descrição (e previsão) de um fato, acompanhada da prescrição de sua consequência jurídica, e não outra regra - e regra sem previsão explícita na ordem jurídica". 
A máxima da proporcionalidade deve ser utilizada diante de um caso duvidoso ou quando a lei a ser aplicada é imprecisa. Como não houve identificação do direito com a lei, quando a lei por si só não estabelece obrigatoriedade, a concepção do que é direito pode (nem sempre é uma necessidade) conduzir a resultados diferentes (ALEXY, 2004, p. 19).

Para Alexy (2004, p. 19), as possibilidades de interpretação não conduzem necessariamente a um único resultado, assim, haverá casos em que a solução será duvidosa. Nesses, a decisão pode ser determinada por elementos extrajurídicos.

\section{Elementos extrajurídicos, uso da moral}

Para conhecer o que são "elementos extra-jurídicos", aplicáveis a um conflito que se apresente, é preciso reconhecer primeiramente o que são elementos jurídicos, o direito em si. "Direito, em sentido jurídico é, no geral, aquilo que as pessoas que convivem em alguma comunidade reconhecem reciprocamente como norma e regra desta convivência" (ALEXY, 2004, p. 19).

Ademais: "Podemos definir o direito como estrutura de um sistema social que se baseia na generalização congruente de expectativas normativas de comportamento" (ALEXY, 2004, p. 24), sendo essas expectativas normativas de comportamento referentes a uma determinada sociedade de um determinado tempo.

Para Alexy (2004, p. 29), o conceito de direito vai além dessa estrutura jurídico normativa, abrangendo o próprio sistema social, baseado no que ele chama de "expectativas normativas de comportamento". Assim, existe uma conexão necessária entre direito e moral.

Há razões normativas que falam em favor de uma inclusão de elementos morais dentro do conceito de Direito. Este não se restringe "norma e regra", mas abrange também a moral daquelas pessoas "que convivem em alguma comunidade e reconhecem reciprocamente (...)" o direito como norma e regra.

Na moral existe a ideia de justiça; o que é justo para uma determinada sociedade pode não o ser para outra e assim sucessivamente. O direito, junto com a moral em Alexy, busca claramente a ideia de justiça. 


\section{Busca da justiça}

Segundo o autor, o caráter jurídico se perde quando a injustiça alcança uma medida insuportável. Assim, deve-se observar, diante de um caso concreto, a norma a aplicar. Caso esta alcance uma medida de injustiça insuportável, não deve ser aplicada a esse caso concreto.

E como reconhecer essa medida injusta? Segundo Alexy (2004, p. 49), a confusão pode surgir porque, em muitos casos, não é fácil traçar a linha divisória entre as normas extremamente injustas e as que não o são.

Ademais, para Alexy (2004, p. 57; 70), um conceito de direito que não negue o caráter jurídico em todos os casos de injustiça, mas que o negue em caso de injustiça extrema, não colocará em risco a segurança jurídica. Para ele: "cuanto más extrema sea bbbla injusticia, tanto más seguro su conocimiento". Assim, somente em casos de extrema injustiça, devido ao seu caráter de fácil reconhecimento, poderia deixar-se de lado o argumento da seguridade jurídica.

Avançando, vemos a junção do que Alexy já havia dito (2004, p. 49). Afinal, como saber os graus dessa injustiça insuportável? Daqui parte a ideia do direito que contenha elementos morais; estaremos diante de uma divisória tênue, que deverá ser resolvida pelo juiz, de forma que sua decisão respeite o direito, a moral e preserve em si a segurança jurídica.

Como conhecer a injustiça? Para Alexy, quanto mais extrema for a injustiça, mais fácil e seguro será o seu conhecimento. Há aqui uma clara junção do conceito material com o conceito epistemológico. Assim, como já visto, nos casos de extrema injustiça, devido ao seu modo relativamente fácil de conhecimento, seria possível deixar de lado o argumento da segurança jurídica.

Alexy abre a estrutura para aceitar elementos extrajurídicos quando haja casos em que prevaleça a dúvida (ALEXY, 2004, p. 74):

Como solo el derecho positivo es derecho, en el âmbito de apertura el juez tiene que decidir em todos los casos dudosos sobre la base de pautas no jurídicas o extrajurídicas. Nesta medida, está autorizado por el derecho positivo - de uma manera básicamente igual a la del legislador - a crear nuevo derecho sobre la base de pautas extrajurídicas. 
Essa criação de "novo direito", feita pelo juiz, baseada em elementos extrajurídicos é que possibilitará o sopesamento de argumentos, a verificação do direito, aquilo que Alexy chama de ponderação. Dessa ideia surgirá a sua teoria, já aqui analisada, da distinção entre regras e princípios, uma vez que a base do argumento dos princípios está justamente na distinção entre regras e princípios. E, a ponderação é a forma característica de aplicação dos princípios. Aqui tudo começa a se ligar e a fazer mais sentido.

\title{
4 Uso da ponderação nas decisões judiciárias - o direito e a moral
}

Alexy atribui ao juiz a competência de decidir um caso em que haja dúvida. Para ele o critério para saber se o juiz se apoia em princípios para fundamentar suas decisões é averiguar se ele leva a cabo a ponderação. Isso porqu, quando alguém realiza alguma ponderação, então necessariamente estará se apoiando em princípios. São, portanto, os princípios, elementos essenciais a um ordenamento jurídico. (ALEXY, 2004, p. 78).

\begin{abstract}
Se hubiese poderado hubiese llegado a outra decisión; pero no he ponderado. Com esto se ve claramente que en todos los sistemas jurídicos en los que existen casos dudosos, en los que la ponderación es relevante, ella está exigida jurídicamente y, por lo tanto, también lo está la consideración de princípios. Esto significa que en todos los sistemas jurídicos de este tipo, por razones jurídicas, los princípios son elementos necessarios del sistema jurídico.
\end{abstract}

Dessa maneira explica-se a ideia colocada por Alexy quando da necessária relação de direito e moral. A presença necessária de princípios no ordenamento jurídico, como demonstrado acima, conduz a uma conexão necessária entre direito e moral, esta é, por Alexy, chamada de "tesis moral" (ALEXY, 2004, p. 79). Sempre com a ponderação, necessária para os casos em que paire a dúvida, encontrar-se-á algum princípio que pertença a alguma moral.

Nos casos de dúvida, deverá o juiz levar em conta todos os princípios relevantes se desejar satisfazer a pretensão de encontrar a "correção" da questão. O que importa aqui é que estes princípios são sempre, ao mesmo tempo, princípios de alguma moral.

Como se incorporaram ao direito os princípios que, por seu conteúdo, são morais, o juiz que se apoia neles decide sobre a base das pautas jurídicas. A decisão do juiz, nos casos 
incertos, tem de ser interpretada de maneira diferenciada. Alexy (2004, p. 80) completa dizendo: "Si se quiere recurrir a la ambígua dicotomia de forma y contenido, se puede decir que el juez decide desde el punto de vista del contenido sobre la base de razones morales y desde el punto de vista de la forma sobre la base de razones jurídicas".

Em seguida, o autor (ALEXY, 2004, p. 81-82) completa a ideia dizendo quê, quando princípios, ou subprincípios, são relevantes em um caso duvidoso, o juiz está juridicamente obrigado a levar a cabo uma otimização referente ao caso concreto. Ao menos uma parte dos argumentos com os quais o juiz fundamenta o resultado de sua ponderação tem por seu conteúdo o caráter dos argumentos morais. Existe assim uma conexão necessária entre o direito e a moral correta, pois a pretensão de correção, necessariamente vinculada com a decisão, inclui uma pretensão de correção moral.

Tal moral deve ser correta, ou seja, fundamentada. Alexy (2004, p. 84) conclui o assunto nos seguintes termos:

Esta idea no es, en modo alguno, vacía. Su vinculacíon con el derecho significa que al derecho pertenecen no solo las reglas especiales de la fundamentacíon jurídica, sino también las reglas generales de la argumentacíon moral, pues lo que es correcto en el âmbito de la moral, lo es en virtud de estas reglas. Más allá de ello, la idea de una moral correcta tiene el carácter de una idea regulativa en el sentido de un objetivo al que hay que aspirar. En esta medida, la pretensíon de corrección conduce a uma dimensíon ideal necesariamente vinculada com el derecho.

Cabe analisar a questão da validade da norma. Primeiramente, que uma norma vale socialmente quando é obedecida, ou, em caso de ser desobedecida, quando implica uma sanção (ALEXY, 2004, p. 87) Uma norma vale moralmente quando está moralmente justificada (ALEXY, 2004, p. 88). Se uma norma não tem qualquer eficácia social, não poderá valer juridicamente. Assim, a validade jurídica de uma norma inclui elementos da validade dessa norma no âmbito social (ALEXY, 2004, p. 8).

Alexy (2004, p. 88) traz outro conceito interessante:

El objeto del concepto ético de validez es la validez moral. Una norma vale moralmente cuando está moralmente justificada. [...] La validez de una norma [...] no se basa ni en su eficácia social ni en su legalidad conforme al ordenamiento, sino exclusivamente en su corrección, que há de ser demonstrada a través de una justificación moral. 
Nos casos extremos, haverá a colisão de normas válidas. É importante saber quê, segundo Alexy, as normas isoladas perdem o seu caráter jurídico se são extremamente injustas. Uma norma injusta não é justificável no sistema. As normas extremamente injustas não podem ter caráter de normas jurídicas (ALEXY, 2004. p. 94).

Há que se falar ainda das normas fundamentais. Essas precedem as leis positivas e fundamentam a competência do legislador, ditando sua validade. Tais normas, segundo Kant (citado por Alexy), conduzem ao dever moral da obediência do direito (ALEXY, 2004, p. 116). A análise do argumento da injustiça tem mostrado que se tem de rejeitar uma prioridade ilimitada do direito positivo: negar caráter jurídico às leis extremamente injustas.

Hoje, as leis não são mais aplicadas somente por subsunção, mas seu conteúdo se revela também por meio da interpretação. Os juízes não baseiam suas fundamentações apenas em rígidos conceitos jurídicos, mas tendem a valorar autonomamente suas decisões, decidindo como colegisladores (ALEXY, 2005, p. 38).

Alexy, em seu livro "Teoria da Argumentação Jurídica", avalia a questão da valoração: "onde e em que medida são necessárias valorações, como deve ser determinada a relação dessas com os métodos da interpretação jurídica e com os enunciados e conceitos da dogmática jurídica, e como podem ser racionalmente fundamentadas ou justificadas essas valorações" (ALEXY, 2005, p. 39).

Costuma-se dizer que as valorações necessárias nas decisões jurídicas devem-se considerar como morais (ALEXY, 2005, p. 39). Hart, conforme explica Alexy, adota a concepção de que o aplicador pode deixar-se guiar, em lugar das razões morais, por qualquer outro objetivo social, seja qual for seu valor moral.

Deve-se separar claramente a questão de se as valorações necessárias nas decisões jurídicas (que não podem ser extraídas diretamente da lei) devem ser consideradas como valorações morais da questão de se as decisões jurídicas em geral podem ser diferenciadas das decisões morais. A última questão deve ser afirmada com firmeza devido ao caráter especial das fundamentações jurídicas presentes nesta teoria do discurso jurídico.

Conclui Alexy (2005, p. 40) que o aplicador deve orientar-se em um sentido juridicamente relevante, de acordo com valorações moralmente corretas. 
À medida que são imprescindíveis valorações à Ciência do Direito e à jurisprudência, haverá também um campo livre para conviç̧ões morais subjetivas dos aplicadores do Direito. Para K. Engisch (citado por Alexy), quem decide tem de se ajustar aos "valores da coletividade ou de círculos determinados" (ALEXY, 2004, p. 41).

Para Alexy, em muitos casos não é possível determinar as valorações da coletividade, mesmo com a ajuda dos métodos das ciências sociais. Assim, com frequência haverá juízos de valores divergentes.

Será preciso sempre questionar se uma conviç̧ão normativa pode ser base justificativa para decisões jurídicas, simplesmente pelo fato de ela ser conhecida pela comunidade. Haverá sempre uma discussão crítica por parte do jurista.

\section{A argumentação jurídica}

Assim, o discurso jurídico exige uma argumentação jurídica baseada em uma série de considerações limitadoras, entre as quais deve-se mencionar especialmente a sujeição à lei, a consideração obrigatória dos precedentes, seu enquadramento na dogmática elaborada pela Ciência do Direito organizada institucionalmente, assim como as limitações das regras do ordenamento processual (ALEXY, 2005, p. 46). Deve assim, o discurso jurídico, ser racionalmente fundamentável sob a consideração dessas condições limitadoras.

Parte-se de convicções normativas para a formação do discurso, bem como de interesses e interpretações das necessidades vislumbradas no caso concreto. A grande tarefa da Teoria do Discurso, exposta por Alexy (2005, p. 47) é:

\footnotetext{
precisamente a de propor regras que, de um lado, sejam tão fracas, isto é, tenham tão pouco conteúdo normativo que pessoas com concepções normativas totalmente diferentes possam estar de acordo com elas, mas que, por outro lado, sejam tão fortes que uma discussão pautada nelas possa ser qualificada como 'racional'.
}

Assim, o discurso jurídico se diferencia do discurso prático justamente por ter tolhida a sua liberdade, visto que essa é limitada pela lei, o precedente e a dogmática e - no caso do processo - pelas leis processuais (ALEXY, 2005, p. 48). 
Todo argumento usado pelo propositor do discurso deve ser fundamentado: tratase de uma regra que pode ser denominada "regra geral da fundamentação" (ALEXY, 2005, p. 194), de forma que sua tese terá valor não somente diante do interlocutor, mas perante qualquer um.

Para Willis Santiago Guerra Filho (2001), Alexy, em sua Teoria da Argumentação Jurídica, é capaz de assegurar a racionalidade (prática) do processo de aplicação do direito. O autor explica que para Alexy é possível destacar que haverá sempre a necessidade de sopesar princípios, além da mera subsunção de fatos a normas, princípios esses que são como as normas, partes do ordenamento jurídico.

O positivismo condena a moral, ele se apega à lei posta, de maneira que não aceita interferência da moral; é assim, a pura aplicação da lei. Robert Alexy pode ser considerado, e o é por alguns autores, um "positivista" que aceita a moral; nesse caso não se trata de uma afirmação científica, é sim de apenas uma constatação.

Isso porque, para Alexy a moral não pode ser simplesmente desconsiderada e "jogada fora". Muito pelo contrário, ela deve ser usada e em casos de injustiças, pode inclusive mudar a norma.

\section{Conclusão}

Em relação à colisão entre princípios e regras, entende Alexy que o conflito entre aqueles e estas se dará diferentemente. Entre regras, não há que se falar em um sopesamento, ou seja, quando entram em conflito, uma sempre prevalecerá sobre a outra. Já na colisão entre princípios é possível falar em uma ponderação. Aqui, um cede ao outro sem que qualquer deles seja considerado inválido. O princípio seria assim um mandamento de otimização.

Adentrando-se as ponderações de Robert Alexy, tem-se a máxima da proporcionalidade que consiste, essencialmente, na verificação dos meios utilizados para a adequação do caso concreto ao fim, por meio da ponderação. Para ele, devido a sua menor generalidade e maior grau de certeza, as regras prevalecem sobre os princípios quando em colisão. 
Alexy desenvolve um método de aplicação da proporcionalidade, qual seja, o de dividi-la em três aspectos: adequação, exigibilidade e proporcionalidade em sentido estrito. Primeiramente ele busca a adequação, uma interpretação dos dispositivos constitucionais; depois prova a exigibilidade do meio, usa o meio mais adequado, aquele que promova menor dano; e por fim fala da proporcionalidade em sentido estrito.

No livro "El concepto y la validez del derecho", Alexy busca a resolução de casos difíceis, aqueles que não encontram solução pela simples aplicação da norma. Busca a inclusão de elementos morais dentro do conceito de direito a fim de solucionar tais conflitos.

Não é simples distinguir entre um caso em que há uma injustiça e outro em que a injustiça é insuportável. O “insuportável” não é de fácil compreensão, não é mensurável e racional. Aqui se estará diante de uma divisória tênue, que deverá ser resolvida pelo juiz, devendo sua decisão respeitar o direito, a moral e preservar a segurança jurídica.

Os elementos jurídicos, nesse caso, aqui permitidos pelo próprio Alexy chamam a ponderação à verificação do direito, ou seja, o sopesamento de argumentos, voltando-se aos conceitos iniciais entre as já elencadas diferenciações entre princípios e regras.

Alexy dá ao juiz a competência de decidir um caso em que haja dúvida, devendo este utilizar-se impreterivelmente da relação de direito e moral, lbogo, do necessário uso de princípios. Nos casos de dúvida, todos os princípios relevantes ao caso deverão ser analisados. Esses princípios do direito são sempre, ao mesmo tempo, princípios de alguma moral.

Assim as normas, não serão interpretadas somente pelo uso da subsunção, mas muito mais pelo uso da interpretação. As decisões judiciais não serão baseadas apenas em rígidos conceitos jurídicos, mas em conceitos que tendem a valorar-se. Os juízes passariam a funcionar no sistema como colegisladores.

A valoração utilizada pelo jurista deve ser no sentido da moral, e de uma moral correta, fundamentada. A moral correta é aquela que se veicula a uma fundamentação alicerçada nos princípios básicos da Lei Fundamental. De forma que o conhecimento Constitucional é elemento essencial para fundamentar uma decisão judiciária correta. 
Correta porque fundamentada; não só com embasamentos teóricos, mas moralmente fundamentada. Logo, jurídica e justa; a verdadeira decisão judiciária.

\section{Referências}

ALEXY, Robert. El concepto y la validez del derecho. 2. ed. Tradução Jorge M. Seña. Barcelona: Gedisa Editorial, 2004.

ALEXY, Robert. Teoria da Argumentação Jurídica: a teoria do discurso racional como teoria da fundamentação jurídica. 2. ed. Tradução de Zilda Hutchinson Schild Silva. São Paulo: Landy Editora, 2005.

ALEXY, Robert. Teoria de los Derechos Fundamentales. Tradução de Ernesto Garzón Valdéz. Madrid: Centro de Estudios Políticos y Constitucionales, 2002.

GUERRA FILHO, Willis Santiago. Princípio da proporcionalidade e devido processo Legal; In.: Silva, Virgílio Afonso da (Org.). Interpretação constitucional. São Paulo Malheiros, 2005.

GUERRA FILHO, Willis Santiago. Teoria da Ciência Jurídica. São Paulo: Saraiva, 2001.

SILVA, Virgílio Afonso da. Princípios e Regras: mitos e equívocos acerca de uma distinção. Revista Latino-Americana de Estudos Constitucionais, v. 1, p. 607-630, 2003.

SILVA, Luíz Virgílio Afonso. O proporcional e o Razoável. Revista dos Tribunais, Ano 1, v. 798, abr. 2002.

Artigo recebido em 12/01/2012 e aprovado para publicação em 25/07/2012. 
